\title{
Recurrent Urethral Carcinoma
}

National Cancer Institute

\section{Source}

National Cancer Institute. Recurrent Urethral Carcinoma. NCI Thesaurus. Code C7508.

The reemergence of urethral carcinoma after a period of remission 